\title{
Identification and characterization of the duck enteritis virus (DEV) US2 gene
}

\author{
J. Gao ${ }^{1,2,3}$, A.C. Cheng ${ }^{1,2,3}$, M.S. Wang ${ }^{1,2,3}$, R.Y. Jia ${ }^{1,2,3}$, D.K. Zhu ${ }^{2,3}$, S. Chen ${ }^{1,2,3}$, \\ M.F. Liu, ${ }^{1,2,3}$, F. Liu ${ }^{3}$, Q. Yang ${ }^{1,2,3}$, K.F. Sun ${ }^{1,2,3}$ and X.Y. Chen ${ }^{2,3}$ \\ ${ }^{1}$ Institute of Preventive Veterinary Medicine, Sichuan Agricultural University, \\ Wenjiang, Chengdu, Sichuan, China \\ ${ }^{2}$ Avian Disease Research Center, \\ College of Veterinary Medicine of Sichuan Agricultural University, Wenjiang, \\ Chengdu, Sichuan, China \\ ${ }^{3}$ Key Laboratory of Animal Disease and Human Health of Sichuan Province, \\ Sichuan Agricultural University, Wenjiang, Chengdu, Sichuan, China \\ Corresponding authors: A.C. Cheng / M.S. Wang \\ E-mail: chenganchun@vip.163.com / shwang@163.com
}

Genet. Mol. Res. 14 (4): 13779-13790 (2015)

Received April 23, 2015

Accepted July 30, 2015

Published October 28, 2015

DOI http://dx.doi.org/10.4238/2015.October.28.40

\begin{abstract}
The US2 protein has been reported to contribute to duck enteritis virus (DEV) infection; however, its kinetics and localization during infection, and whether it is a component of virion, have not been previously reported. To elucidate the function of DEV US2, US2 was amplified by polymerase chain reaction (PCR) and inserted into pET-32a(+); this was expressed, the recombinant US2 protein was purified, and a polyclonal antibody generated. In addition, the kinetics and localization of the US2 gene and protein were determined by quantitative real-time fluorescent PCR, ganciclovir (GCV), and cycloheximide (CHX) treatment, westernblot, and indirect immunofluorescence assay. The packaging of US2 into DEV virions was revealed by a protease protection assay. US2 was found to be transcribed $24 \mathrm{~h}$ post-infection (pi) and peaked at $72 \mathrm{~h}$ pi; the US2 protein was detected $48 \mathrm{~h} \mathrm{pi}$, except in the presence of GCV or CHX. US2 was packed into virions and also localized to the plasma membrane and
\end{abstract}


cytoplasm in infected cells. The results showed that the DEV US2 is a late gene, and that its encoding protein could be a tegument component localized mainly in the cytoplasm. This study provides useful data for the further analysis of DEV US2, including an explanation for the genetic conservation among alphaherpesviruses.

Key words: DEV; US2; Tegument; Late gene; Localization

\section{INTRODUCTION}

Duck enteritis virus (DEV) is a globular virus that possesses a viral envelope, tegument, and a nucleocapsid. The virus is composed of a linear, double-stranded DNA with a G+C content of $44.89 \%$, and has been completely sequenced by Wu et al recently (Tirath and Sandhu, 2008; Wu et al., 2012). The Chinese virulent DEV strain is a wild-type virulent strain available in GenBank with the accession No. JQ647509.

Homologs of the alphaherpesvirus US2 are found in herpes simplex virus-2 (HSV-2), canine herpesvirus (CHV), bovine herpesvirus-1 (BHV-1), duck enteritis virus (DEV), Marek's disease virus (MDV), pseudorabies virus (PRV), and equine herpesvirus-1 (EHV-1), among others (Cantello et al., 1991; Haanes and Tomlinson, 1998; Jiang et al., 1998; Belknap et al., 1999; Meindl and Osterrieder, 1999; Ben-Arieh et al., 2001; Clase et al., 2003; Gao et al., 2012b). The properties of US2 have not been extensively studied, despite the fact that it is conserved among alphaherpesviruses (Clase et al., 2003). Duck plague (DP), an acute and contagious infectious disease affecting ducks, swans, and geese, caused by the duck enteritis virus, is responsible for significant losses in agricultural industries (Tirath and Sandhu, 2008; Wu et al., 2012).

Recent studies have suggested that US2 is involved in the penetration and cell-to-cell spread of DEV in susceptible cells (Wei et al., 2013). It is conceivable that US2 plays an important role in the spread of virus; however, the characteristics of US2 remain unclear. In this study, a prokaryotic expression vector was constructed, US2 was expressed in a prokaryotic system, recombinant US2 protein was purified, and a polyclonal antibody was generated to analyze the transcriptional level of the DEV US2 gene and the intracellular localization of the US2 protein in infected cells. Additionally, ganciclovir (GCV) and cycloheximide (CHX) treatment was used to classify the kinetics of US2 gene expression (Wu et al., 2011). The transcriptional level and western blot of US2 in infected cells was also used to confirm the kinetics of US2. Finally, in order to determine if the DEV US2 protein was packaged into virions, extracellular virions were purified and subjected to a protease protection assay. The goal of these experiments was to functionally elucidate the US2 gene and protein; these findings may provide more information facilitating further exploration of the molecular mechanism of US2 recruitment.

\section{MATERIAL AND METHODS}

\section{Virus, cells, serum, enzymes, and plasmids}

The CHv-DEV strain has been previously isolated and identified in our laboratory (Cheng et al., 2006). Duck embryo fibroblast (DEF) monolayer cells were cultured in Eagle's minimal essential medium (MEM) (Gibco, Life technologies, Burlington, ON, CA) supplemented with $10 \%$ 
fetal bovine serum at $37^{\circ} \mathrm{C}$ in a $5 \% \mathrm{CO}_{2}$ environment. MEM was supplemented with $2 \% \mathrm{FBS}$ when cell monolayers were incubated with DEV. Both the CHv-DEV strain and rabbit anti-DEV IgG were obtained from the Key Laboratory of Animal Disease and Human Health of Sichuan Province. All enzymes used in the cloning procedures were purchased from TaKaRa Bio Inc. (Dalian, China). In addition, Escherichia coli DH5a (Tiangen, Beijing, China), E. coli BL21 (DE3) (Tiangen), pMD18$\mathrm{T} / \beta$-actin vector, and the pET-32a(+) expression vector (Novagen, Shanghai, China) were stored in our laboratory.

\section{PCR amplification and plasmid construction}

The US2 open reading frame of DEV (GenBank accession No. EU195086), including the methionine start codon, was amplified from CHv-DEV by PCR, using primers containing the EcoRI and HindIII sites, as previously described (Wu, 2011). The primers were designed by Oligo6 as follows: (P1) forward primer: 5'-G^AATTCATGGGTGTGGTTATATTGT-3' and (P2) reverse primer: 5'-A^AGCTTCTAACAGGCTATACAAC-3'. The PCR products were digested with EcoRI and HindIII (TaKaRa Bio Inc., Dalian, China), and ligated to similarly digested pMD-18T (TaKaRa Bio Inc., Dalian, China) and pET-32a(+). All constructs were confirmed by DNA sequencing (Invitrogen, Carlsbad, CA, USA).

\section{Expression and purification of recombinant US2 protein}

The recombinant expression plasmid pET-32a(+)/US2 was transformed into $E$. coli BL21; the bacterial cell production was induced using optimized amounts of isopropyl- $\beta-D$ thiogalactopyranoside (IPTG) for $3 \mathrm{~h}$ at $37^{\circ} \mathrm{C}$. The resulting recombinant US2 protein was then purified as previously described (Xie et al., 2010). Briefly, the cells were centrifuged at 10,000 rpm for $10 \mathrm{~min}$, resuspended in $20 \mathrm{mM}$ Tris buffer $(\mathrm{pH} 8.0)$ containing lysozyme $(0.1 \mathrm{mg} / \mathrm{mL})$, and subsequently incubated at $-20^{\circ} \mathrm{C}$ overnight. The cell lysate was sonicated on ice for $5 \mathrm{~min}$, at an amplitude of $30 \%$ and a pulse frequency of $30 \mathrm{~s}$, using an ultrasonic instrument (ultrasomic processor-500, Autoscience instrument Co., Ltd., Tian Jing, China). The sonicated lysate was centrifuged at $12,000 \mathrm{rpm}$ for $10 \mathrm{~min}$, and the supernatant and pellets were collected for sodium dodecyl sulfate polyacrylamide gel electrophoresis (SDS-PAGE). The results indicated that the recombinant US2 protein had formed inclusion bodies. The pellets were then resuspended in 20 $\mathrm{mL}$ urea washing buffer (6 M urea, $50 \mathrm{mM}$ Tris- $\mathrm{HCl}, 1 \mathrm{mM}$ EDTA, $150 \mathrm{mM} \mathrm{NaCl}$, and 0.1\% Triton $\mathrm{X}-100$; $\mathrm{pH}$ 8.0) under constant stirring for $10 \mathrm{~min}$, and subsequently centrifuged at $12,000 \mathrm{rpm}$ for $10 \mathrm{~min}$ at $4^{\circ} \mathrm{C}$. The above steps were repeated six times in order to release the trapped protein. The suspension was finally centrifuged at $12,000 \mathrm{rpm}$ for $10 \mathrm{~min}$ at $4^{\circ} \mathrm{C}$, and resuspended in denaturing buffer containing $8 \mathrm{M}$ urea, prior to SDS-PAGE analysis.

\section{Identification of recombinant US2 protein by western blot analysis}

The reactivity and specificity of the recombinant US2 protein was determined by western blot analyses using the purified recombinant US2 protein, as described previously (Towbin et al., 1992). The purified US2 protein was loaded onto a $12 \%$ SDS-PAGE and transferred by electroblotting onto a polyvinylidene difluoride (PVDF) membrane (Millipore) according to the manufacturer protocols. The membranes were incubated for $1 \mathrm{~h}$ with primary rabbit anti-DEV IgG, 
washed thrice with PBST, and finally incubated with horseradish peroxidase (HRP)-labeled goat anti-rabbit secondary $\lg (1: 5000)$ for $30 \mathrm{~min}$ at $37^{\circ} \mathrm{C}$. The membranes were then washed thrice with PBST, and treated with 3,3'-diaminobenzidine (DAB) (Zhongshan Co. Ltd., Beijing, China) in $0.1 \% \mathrm{H}_{2} \mathrm{O}_{2}$.

\section{Generation of rabbit anti-US2 IgG}

Rabbit anti-US2 polyclonal antibodies were prepared as previously described (Xiang et al., 2010; Wu et al., 2011). Briefly, male New Zealand white rabbits were immunized intradermally with a mixture of $0.5 \mathrm{mg}$ purified US2 protein and an equal amount of complete Freund's adjuvant (Sigma-Aldrich, Shanghai, China). Two weeks later, $0.75 \mathrm{mg}$ of the purified US2 protein and an equal amount of Freund's incomplete adjuvant were administered for secondary immunity. The rabbits were boosted subcutaneously with $1.0 \mathrm{mg}$ each of purified US2 protein and incomplete Freund's adjuvant at 1 week intervals. The rabbits were injected intravenously with $0.1 \mathrm{mg}$ purified US2 protein after 7 days, and the serum was subsequently collected after 17 days. Pre-immune serum was obtained from non-vaccinated healthy rabbits as a control.

Agar diffusion reactions were used to detect the antiserum titer (Lu et al., 2010; Wu et al., 2011). Briefly, $1 \mathrm{~g}$ agar was dissolved in $100 \mathrm{~mL} 0.85 \%$ sodium chloride. The mixture was heated, cooled to $55^{\circ} \mathrm{C}$, and then poured into plates to a thickness of $2 \mathrm{~mm}$. The agar was perforated with holes ( $3 \mathrm{~mm}$ diameter) that could hold approximately $100 \mu \mathrm{L}$ of solution. Forty microliter each of the pre-immune serum, mock, 1:2, 1:4, 1:8, 1:16, and 1:32 diluted antiserum were added into the peripheral wells. Finally, $20 \mu \mathrm{L}$ of purified US2 protein was added to the central well. The plate was incubated at $37^{\circ} \mathrm{C}$ for $10 \mathrm{~h}$ before observation.

The rabbit IgG fraction was precipitated from the harvested rabbit polyclonal antiserum by ammonium sulfate precipitation and High-Q anion-exchange chromatography, according to the manufacturer protocols (McGuire et al., 1996).

\section{US2 expression in infected cells}

The US2 expression was detected by western blot as previously described (Clase et al., 2003). Briefly, confluent monolayers of DEFs were infected and mock-infected with DEV, and harvested at $12,24,36,48,60,72$, and $84 \mathrm{~h}$ post infection (pi) to determine the level of US2 expression in infected cells. At the indicated times, the medium was removed and the cells washed thrice with PBS. The cells were scraped into $40 \mu \mathrm{L}$ PBS and transferred to a $1.5 \mathrm{~mL}$ microfuge tube containing $10 \mu \mathrm{L}$ SDS-PAGE sample buffer. Aliquots were heated to $100^{\circ} \mathrm{C}$ for 10 min, electrophoresed through $12 \%$ SDS-PAGE gels, and analyzed by western blot using polyclonal antiserum against US2 (Clase et al., 2003; Xiang et al., 2010). In this case, the purified DEV US2 IgG was used as the primary antibody for dynamic expression analyses.

\section{Indirect immunofluorescence assay}

Indirect immunofluorescent assay was performed as previously described (Clase et al., 2003; Zhao et al., 2008; Shen et al., 2009; Kang and Banfield, 2010; Xing et al., 2011). DEF cells were seeded onto glass coverslips and grown to a confluence of $30-40 \%$ prior to mock infection or infection with DEV in 6-well plates. The cells were washed with PBS 39, 49.5, 60, 72.5, and $84 \mathrm{~h} \mathrm{pi}$, 
and subsequently fixed with $4 \%$ paraformaldehyde-PBS for $30 \mathrm{~min}$ at room temperature. The cells were rinsed with PBS and permeabilized in PBS containing $0.1 \%$ Triton X-100 for 10 min at room temperature. The cells were then washed with PBS, blocked for $1 \mathrm{~h}$ in PBS containing $5 \%$ BSA at $37^{\circ} \mathrm{C}$, and incubated with purified US2 antiserum or pre-immune serum $(1: 50)$ at $4^{\circ} \mathrm{C}$ overnight. The cells were washed three times for $10 \mathrm{~min}$ in PBS, and treated with fluorescein isothiocyanate (FITC)-conjugated goat anti-rabbit IgG (Zhongshan Co. Ltd., Shanghai, China) for 45 min at $37^{\circ} \mathrm{C}$. The cell nuclei were visualized by 4',6-diamidino-2-phenylindole (DAPI) counter-staining ( $5 \mu \mathrm{g} / \mathrm{mL}$; Beyotime Institute of Biotechnology, Shanghai, China) as previously described (Miller et al., 2000). Coverslips were mounted on glass slides, and the images were captured using a fluorescence microscope imaging system (Nikon 80; Nikon, Tokyo, Japan).

\section{Protease treatment of purified virions}

Virions were purified using previously described procedures (Clase et al., 2003; Lyman et al., 2006; Xie et al., 2009) by ultra-centrifugation (Beckman LE-80K). Briefly, the virions were treated with proteinase $\mathrm{K}(10 \mu \mathrm{g} / \mathrm{mL})$ in the presence and absence of SDS (1\%). Four experimental samples were prepared: (1) $20 \mu \mathrm{L}$ virion suspension with $10 \mu \mathrm{L}$ SDS and $20 \mu \mathrm{L}$ proteinase K; (2) 20 $\mu \mathrm{L}$ virion with $10 \mu \mathrm{L}$ SDS and $20 \mu \mathrm{L}$ PBS; (3) $20 \mu \mathrm{L}$ virions with $20 \mu \mathrm{L}$ proteinase $\mathrm{K}$ and $10 \mu \mathrm{L}$ PBS; and (4) $50 \mu \mathrm{L}$ PBS. Phenylmethanesulfonyl fluoride (PMSF) was added to each sample after $1 \mathrm{~h}$ incubation at room temperature, to inhibit further reactions. The samples were analyzed by SDSPAGE and transferred to a PVDF membrane for western blot detection of US2 and UL51.

\section{Transcriptional levels of the US2 gene}

The DEV CHv strain was propagated in DEFs. The levels of the mRNA transcripts of US2 were determined by a rapid real-time quantitative polymerase chain reaction (qRT-PCR) using an Icycler IQ Real-time PCR Detection System (Bio-Rad, Hercules, CA, USA) coupled with SYBR Green chemistry. Total RNA was extracted from DEV infected DEFs at different times: 12, 24, 36, 48, 60, 72, 84, and $96 \mathrm{~h}$ pi using the Total RNA Isolation kit (TaKaRa Bio Inc.); the RNA was reverse transcribed to cDNA. The primers used for qRT-PCR were $\triangle$ US2 F (5'-AGACGGTTCCGAAAGTACAG-3') and US2 R (5'-TCGGCAGCACCAATAATCC-3'), $\beta$-actin F (5'-CCGGGCATCGCTGACA-3') and $\beta$-actin $\mathrm{R}$ (5'-GGATTCATCATACTCCTGCTTGCT-3'). The in vitro transcriptional level of the DEV US2 gene was detected by a previously described qRT-PCR process (Lian et al., 2010). The optimized $20 \mu \mathrm{L}$ real-time PCR mixture comprised $1 \mu \mathrm{L}(10 \mathrm{pM})$ of each primer, $1 \mu \mathrm{L}$ DNA template, 10 $\mu \mathrm{L}$ SYBR Green I Mix, and $7 \mu \mathrm{L}$ autoclaved double-filtered nanopure water. The template was replaced with water for no-template controls. The qRT-PCR program consisted of an initial 5 min denaturation step at $95^{\circ} \mathrm{C}$, followed by 45 cycles of denaturation $\left(94^{\circ} \mathrm{C}, 30 \mathrm{~s}\right)$, annealing $\left(61^{\circ} \mathrm{C}\right.$, $30 \mathrm{~s})$, and extension $\left(72^{\circ} \mathrm{C}, 30 \mathrm{~s}\right)$. The relative fluorescence and melt curve was measured. The relative amount of the US2 mRNA expression was measured by the $2^{-\Delta \Delta \mathrm{Ct}}$ method. Each reaction of DEV US2 and $\beta$-actin was optimized in triplicate based on their primers (Qing et al., 2010).

\section{Ganciclovir and cycloheximide treatment}

The samples were treated with GCV and $\mathrm{CHX}$ as previously described (Huang and Wu, 2004; Luo et al., 2012). Briefly, confluent monolayers of DEF cells growing in $25 \mathrm{~cm}^{2}$ cell culture 
flasks were treated with GCV and CHX. The cell culture medium was replaced with MEM-10\% FBS with or without GCV (KeLun, Hu Nan, China) or CHX (Sigma-Aldrich). The cells were infected with DEV and incubated in the presence or absence of $300 \mu \mathrm{g} / \mathrm{mL}$ of GCV or $100 \mu \mathrm{g} / \mathrm{mL} \mathrm{CHX}$ for $36 \mathrm{~h}$. Total RNA was extracted from the cell lysates and reverse transcribed using the PrimeScript ${ }^{\mathrm{TM}} \mathrm{RT}$ reagent Kit (TaKaRa). The $\triangle \mathrm{US} 2$ and $\beta$-actin primers were used to detect the cDNA templates by normal PCR.

\section{RESULTS}

\section{Expression and purification of recombinant US2 protein}

The recombinant plasmid pET-32a(+)/US2 expressed a considerable amount of a $46 \mathrm{kDa}$ protein, while the same band was absent when induced from the empty pET32a $(+)$ control vector (Figure 1A). The recombinant US2 protein was purified in washing buffer by continuous stirring, separated by SDS-PAGE, and analyzed by staining with Coomassie brilliant blue. This allowed for the visualization of a high purity US2 protein band, compared to the BSA controls (Figure 1B).
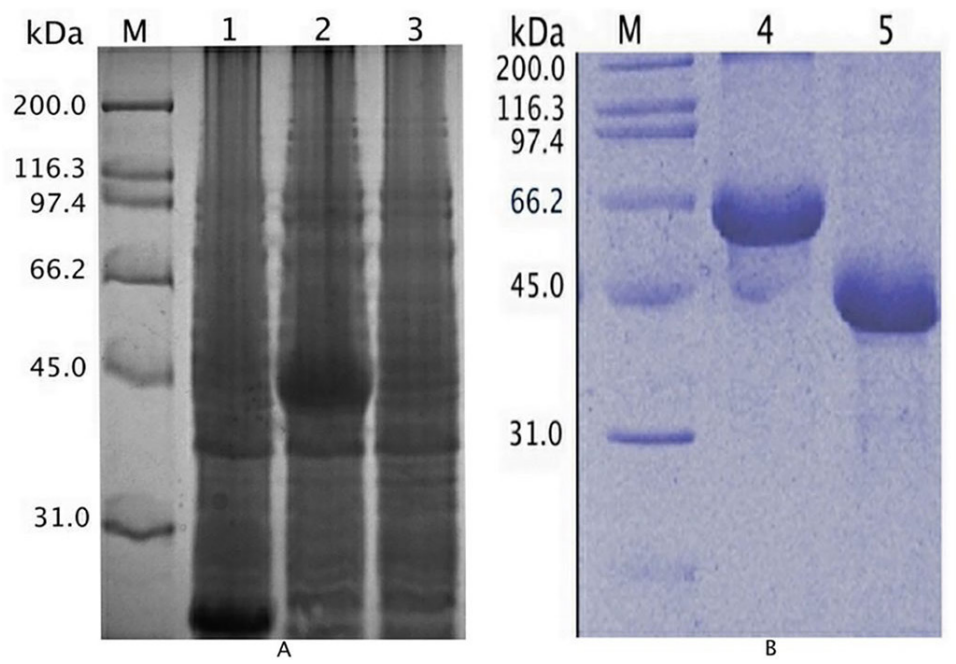

Figure 1. Analysis of the expression and purification of fusion protein DEV US2 by SDS-PAGE. A. Lane $M=$ protein marker; lane $1=$ the total proteins of cells harboring plasmid pET-32a $(+)$ induced by IPTG treatment; lane $2=$ the total proteins of cells harboring plasmid pET-32a(+)/US2 induced by IPTG; lane $3=$ the total proteins of cells harboring plasmid $\mathrm{pET}-32 \mathrm{a}(+) / \mathrm{US} 2$ without IPTG induction. B. Lane $4=$ bovine serum albumin $(\mathrm{BSA})$ standard $(1 \mathrm{mg} / \mathrm{mL})$; lane $5=$ the purified fusion US2 protein.

\section{Identification of US2 by western blot and agar diffusion reaction}

Rabbit polyclonal antiserum against DEV was used in the western clot identification of the recombinant US2 protein. The estimated molecular mass of the recombinant DEV US2 protein (determined by SDS-PAGE) was approximately $46 \mathrm{kDa}$ (Figure $2 \mathrm{~A}$ ). The agar diffusion reaction precipitating line indicated that the largest positive dilution of rabbit anti-US2 antiserum was 1:16 (Figure 2B). Pre-immune serum, which was used as a negative control, showed no antigenantibody complexes in both SDS-PAGE and agar diffusion assays. 


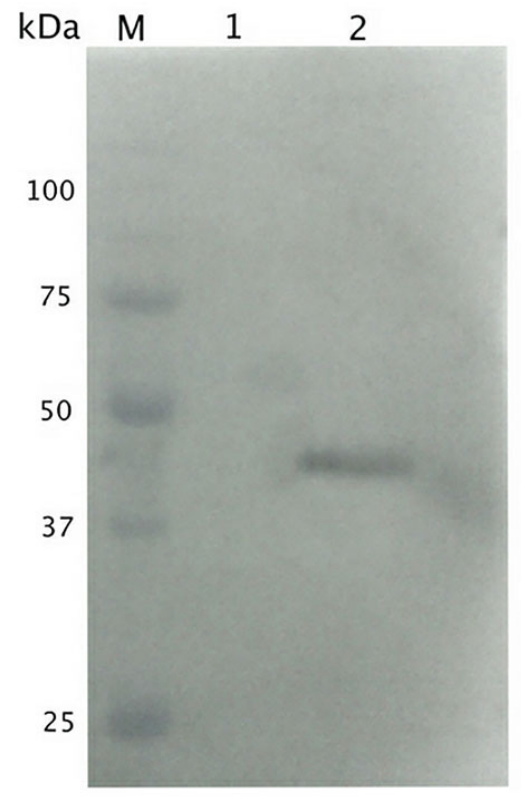

A

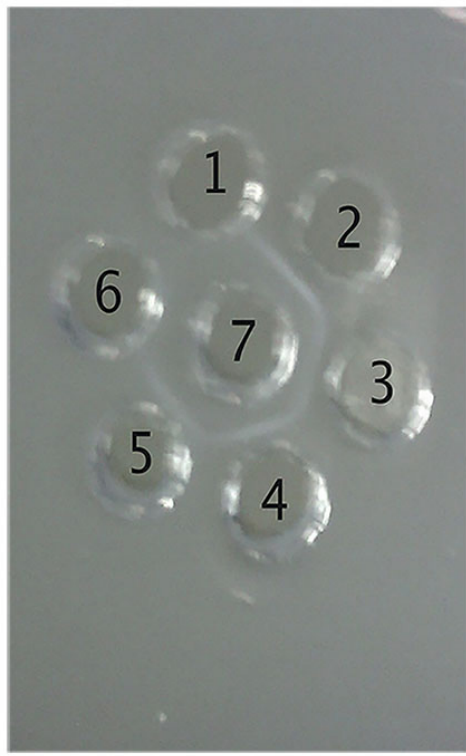

B

Figure 2. Identification of DEV US2 protein and analysis of the antiserum titer by agar diffusion. A. Recombinant US2 expression was analyzed by western blot using rabbit anti-DEV IgG. B. Agar diffusion reaction was designed to determine the specificity and sensitivity of anti-US2 serum, and the results of the agar diffusion reaction of the antiUS2 serum with purified US2 protein suggested that the largest dilution was 1:16. Lane $M=$ protein marker; lane $1=$ western blot of the total proteins extracted from cells harboring the plasmid $p E T-32 a(+) / U S 2$ without IPTG induction; lane 2 = western blot of the total proteins of cells harboring pET-32a(+)/US2 with IPTG induction; 1, rabbit pre-serum; 2, 2-fold diluted antiserum; 3, 4-fold diluted antiserum; 4, 8-fold diluted antiserum; 5, 16-fold diluted antiserum; 6, 32fold diluted antiserum; and 7 , purified US2 protein.

\section{Kinetics of DEV US2}

The US2 gene expression in the presence of GCV and CHX was analyzed. US2 expression was not observed when cells were treated with GCV or $\mathrm{CHX}$, while the DEV-infected cells without DNA or protein inhibitors showed a US2 signal (Figure 3A). The transcriptional level of DEV US2 in non-inhibited cells (Figure $3 B$ ) revealed that US2 mRNA expression was relatively low 24-36 h $\mathrm{pi}$, increased after $48 \mathrm{~h} \mathrm{pi,} \mathrm{peaked} \mathrm{at} 72 \mathrm{~h} \mathrm{pi}$, and then decreased. In addition, the US2 protein was first detected in cell lysates by western blot $48 \mathrm{~h}$ after infection (Figure 4). Taken together, this data suggests that the US2 protein is expressed during late kinetics.

\section{Protease protection assay}

Treated virions were subjected to SDS-PAGE, and US2 was detected by western blot. As shown in Figure 5A (lane 1), US2 protein was susceptible to digestion when virions were treated with both SDS and protease $\mathrm{K}$, and remained unaffected when treated with protease $\mathrm{K}$, SDS, or PBS alone (lanes 2 to 4). UL51, a known tegument protein, was used as a control (Figure 5B). 


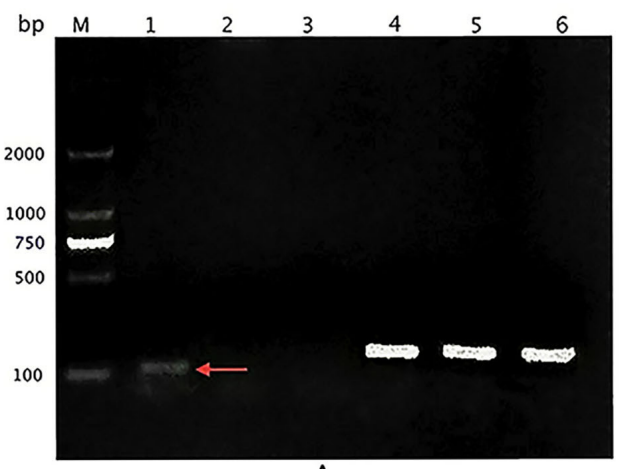

A

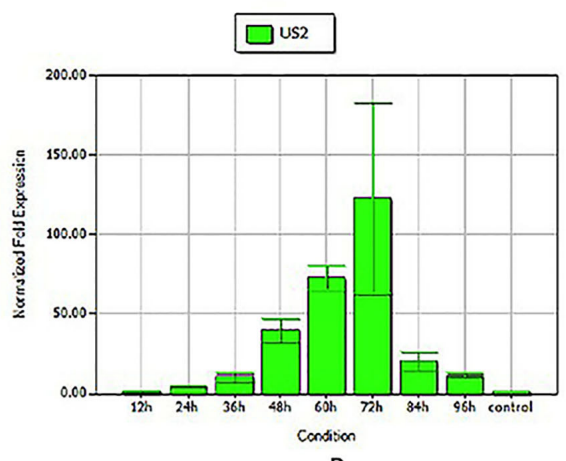

B

Figure 3. Results of the nucleic acid inhibition and transcriptional expression of the US2 gene. A. Lane M = DNA marker. DEF was infected with DEV in the presence of $300 \mu \mathrm{g} / \mathrm{mL}$ ganciclovir or $100 \mu \mathrm{g} / \mathrm{mL}$ cycloheximide and the total RNA of infected cells was harvested at $36 \mathrm{~h}$ post infection. RNA was reverse transcribed into cDNA and detected by $P C R$ using primers specific for the US2 and $\beta$-actin genes. Lanes 1 to $3=P C R$ using $\triangle U S 2$ gene primers on templates from DEV-infected DEF cells in the presence of PBS, GCV, and CHX respectively. Lanes 4 to $6=$ the results of PCR using $\beta$-actin primers (templates were identical to the ones used on lanes 1-3). B. Relative content of the US2 mRNA was calculated at $12,24,36,48,60,72,84$, and $96 \mathrm{~h}$ pi using the $2^{\Delta \Delta \mathrm{Ct}}$ method.

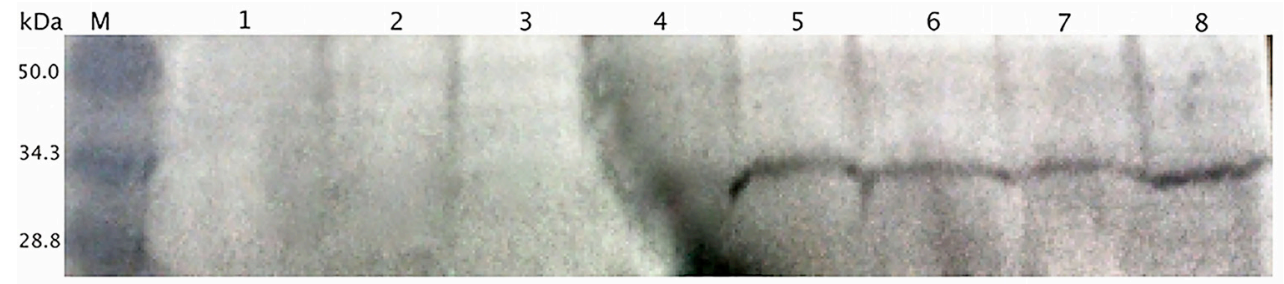

Figure. 4. Western blot analysis of US2 expression in DEV infected cells. Lane $M=$ marker; lane $1=$ mock infection; lanes $2-8=$ times post-infection $(12,24,36,48,60,72,84 \mathrm{~h}$ pi). The US2 protein was first detected by western blot 48 $\mathrm{h}$ after infection, and the specific band corresponded to the expected molecular weight of DEV US2 ( 30 kDa).
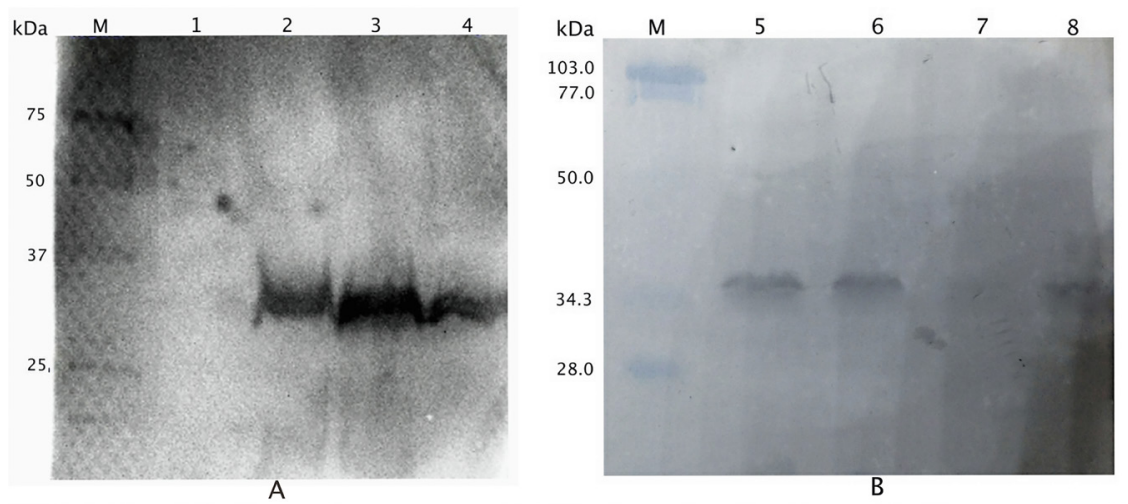

Figure 5. Western blot of purified virus analyzed for US2 and UL51 through protease protection assay. Lane $M=$ marker; lane 1 = DEV virions treated with SDS and Protease $\mathrm{K}$; lane 2 = DEV virions treated with protease $\mathrm{K}$ alone; lane $3=\mathrm{DEV}$ virions treated with SDS; lane $4=\mathrm{DEV}$ virions treated with PBS alone as a control; lane $5=\mathrm{DEV}$ virions treated with protease $\mathrm{K}$ alone; lane $6=\mathrm{DEV}$ virions treated with SDS; lane $7=\mathrm{DEV}$ virions in the presence of both SDS and protease $\mathrm{K}$; lane $8=\mathrm{DEV}$ virions treated with PBS alone as a control. 


\section{Localization of the US2 protein}

US2 was sporadically distributed on the plasma membrane (Figure 6) at $39 \mathrm{~h}$ pi and $49.5 \mathrm{~h}$ pi US2 was localized in the cytoplasm of infected cells at $60 \mathrm{~h}$ pi (Figure 7A); the fluorescence was enhanced and localized mainly in the cytoplasm near the nucleus at $84 \mathrm{~h}$ pi (Figure 7B).
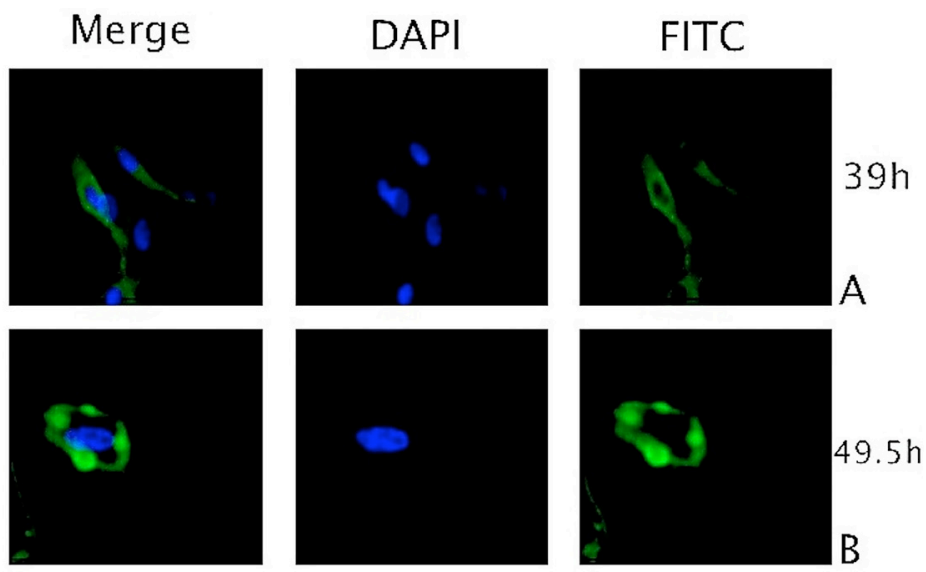

Figure 6. Intracellular localization of US2. DEV-infected cells were fixed at $39 \mathrm{~h}$ pi and $49.5 \mathrm{~h}$ pi. The samples were incubated with anti-US2 IgG and subsequently stained with a FITC-conjugated secondary antibody. Nuclei were counterstained with DAPI (blue).
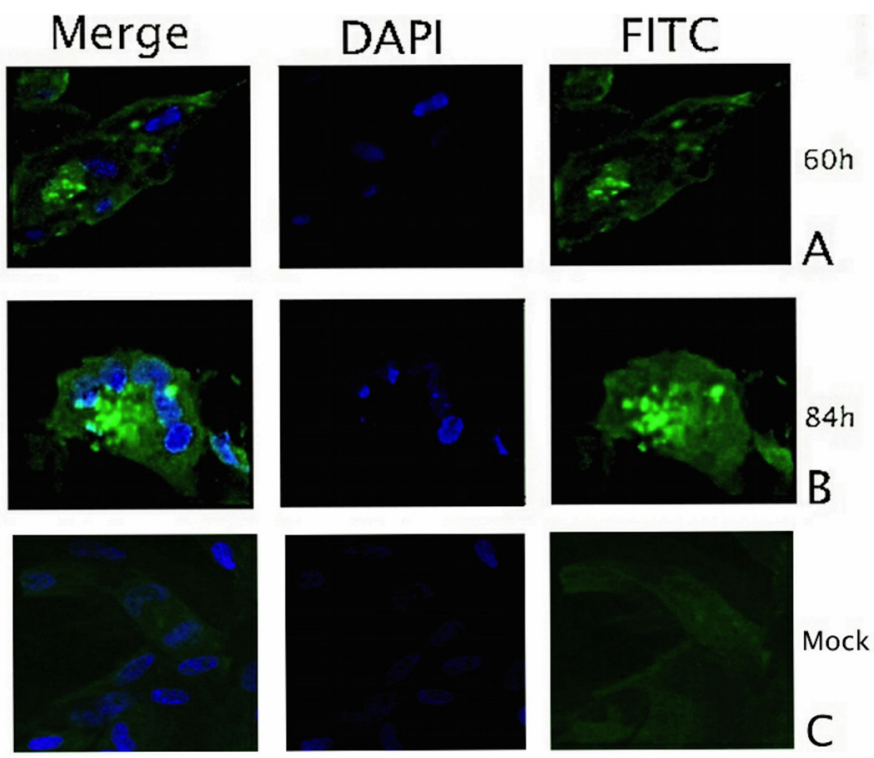

Figure 7. Intracellular localization of US2. DEV-infected cells were fixed at $60 \mathrm{~h}$ pi and $84 \mathrm{~h}$ pi. The samples were incubated with anti-US2 serum and subsequently stained with a FITC-conjugated secondary antibody. Nuclei were counterstained with DAPI (blue). C represents a sample from mock-infected DEF, which was processed and analyzed as a control. 


\section{DISCUSSION}

This report presents the detailed characterization of the DEV US2 protein. Unlike PRV US2, expression of DEV US2 is sensitive to the DNA synthesis inhibitor ganciclovir (GCV), which suggests that DEV US2 is a late gene. DNA synthesis in herpesvirus-infected cells is significantly reduced by ganciclovir treatment, whereas ganciclovir had little effect on DNA synthesis in mock cells (St Clair et al., 1987). Herpesvirus genes are grouped into three types ( $\alpha$, $\beta$, and $\gamma$ genes) according to their transcription kinetics (Workman et al., 1988; Dunn et al., 2003; van Beurden et al., 2013). Immediate-early genes (IE/ $\alpha$ genes) are the first viral genes expressed, early genes (E/ $\beta$ genes) are expressed prior to viral DNA replication, and late genes (L/Y genes) are dependent on viral replication. We examined the synthesis of US2 in the presence of GCV, an inhibitor of viral DNA synthesis or $\mathrm{CHX}$, an inhibitor of protein synthesis, to determine the kinetics of US2. US2 was seen to be affected by both GCV and $\mathrm{CHX}$ (Figure $3 \mathrm{~A}$ ), indicating that US2 is a late gene dependent on viral replication for its expression.

Transcription of DEV US2 mRNA was at a low level from 24 to $36 \mathrm{~h}$ pi (Figure 3B), and increased $48 \mathrm{~h}$ pi, with a peak at $72 \mathrm{~h}$ pi. In addition, the DEV US2 protein was detectable by western blot at $48 \mathrm{~h}$ pi. The results of transcriptional level and dynamic expression analyses confirmed that US2 is a late gene (Geballe et al., 1986).

IF assay revealed the presence of DEV US2 in the plasma membrane and cytoplasm adjacent to the nucleus of infected cells. We determined the location of US2 at different times from $39 \mathrm{~h}$ to $84 \mathrm{~h}$ pi to further elucidate the dynamic process of US2 protein in cell. Wei et al. (2013) revealed a time point during the infection when US2 was localized in the cytoplasm; the results of our study agrees with this observation. In addition, the dynamic expression process of US2 was highlighted in this study. In brief, this study revealed the specific dynamic characteristics of US2 (from the CHv-DEV virulent strain).

Similarly, the EHV-1 and PRV US2 proteins were also localized on the plasma membrane despite lacking an obvious signal sequence or transmembrane domain. In contrast, HSV-2 US2 was shown to be localized in the cytoplasm and discrete granules within and at the periphery of the nucleus, instead of the plasma membrane. Our results suggest a dynamic change in the intracellular localization of US2 during the course of DEV infection; specifically, US2 was observed to be localized at the plasma membrane despite lacking a classical $\mathrm{N}$-terminal signal sequence or a putative transmembrane domain (Gao, 2012a). However, a C-terminal CAAX motif, which is a common site for protein prenylation and is associated with plasma membrane localization as in PRV US2, was identified (Jung and Desrosiers, 1991; Kato et al., 1992; Kang and Banfield, 2010). Plasma membrane association is promoted by a series of three closely linked posttranslational modification steps signaled by the consensus carboxyl-terminal CAAX motif $(C=$ cysteine; $A=$ any aliphatic amino acid; $X=$ any amino acid)(Kang and Banfield, 2010). Accordingly, we suspect that the plasma membrane association may be driven by the CAAX motif, as it could provide a site for lipid modification, thereby facilitating its association with the plasma membrane.

Protease protection assays indicated that US2 is a component of the DEV virion, which is only digested by protease $\mathrm{K}$ when the lipid envelope is treated by SDS; therefore, we concluded that the US2 protein could be a tegument component.

In summary, DEV US2 is a late gene expressing a $\sim 30 \mathrm{kDa}$ protein, which could be a tegument component that is mainly localized in the cytoplasm. Additionally, the US2 protein was also associated with membranes although it has no obvious $\mathrm{N}$-terminal signal sequence or a transmembrane domain. 


\section{Conflicts of interest}

The authors declare no conflict of interest.

\section{ACKNOWLEDGMENTS}

Research supported by grants from the National Science and Technology Support Program for Agriculture (\#2015BAD12B05), the China Agricultural Research System (CARS-43-8) and the Innovative Research Team Program of the Education Department of Sichuan Province (\#12TD005/2013TD0015).

\section{REFERENCES}

Belknap EB, Walters LM, Kelling C, Ayers VK, et al. (1999). Immunogenicity and protective efficacy of a gE, gG and US2 genedeleted bovine herpesvirus-1 (BHV-1) vaccine. Vaccine 17: 2297-2305.

Ben-Arieh SV, Zimerman B, Smorodinsky NI, Yaacubovicz M, et al. (2001). Human cytomegalovirus protein US2 interferes with the expression of human HFE, a nonclassical class I major histocompatibility complex molecule that regulates iron homeostasis. J. Virol. 75: 10557-10562.

Cantello JL, Anderson AS, Francesconi A and Morgan RW (1991). Isolation of a Marek's disease virus (MDV) recombinant containing the lacZ gene of Escherichia coli stably inserted within the MDV US2 gene. J. Virol. 65: 1584-1588.

Cheng A, Wang M, Wen M, Yang Q, et al. (2006). Construction of duck enteritis virus gene libraries and discovery, cloning and identification of viral nucleocapsid protein gene. High Technol. Lett. 16: 948-953.

Clase AC, Lyman MG, del Rio T, Randall JA, et al. (2003). The pseudorabies virus us2 protein, a virion tegument component, is prenylated in infected cells. J. Virol. 77: 12285-12298.

Dunn W, Chou C, Li H, Hai R, et al. (2003). Functional profiling of a human cytomegalovirus genome. Proc. Natl. Acad. Sci. U. S. A. 100: 14223-14228.

Gao J, Cheng AC and Wang MS (2012a). Bioinformatics analysis and characteristics of US2 protein encoded by the newly identified US2 gene of duck enteritis virus. Adv. Mater. Res. 424-425: 493-497.

Gao J, Cheng A and Wang M (2012b). Characterization of US2 gene and its encoding protein from Herpesvirus. Rev. Med. Microbiol. 23: 58-62.

Geballe AP, Leach FS and Mocarski ES (1986). Regulation of cytomegalovirus late gene expression: gamma genes are controlled by posttranscriptional events. J. Virol. 57: 864-874.

Guo Y, Cheng A, Wang M and Zhou Y (2009). Purification of anatid herpesvirus 1 particles by tangential-flow ultrafiltration and sucrose gradient ultracentrifugation. J. Virol. Methods 161: 1-6.

Haanes EJ and Tomlinson CC (1998). Genomic organization of the canine herpesvirus US region. Virus Res. 53: 151-162.

Huang C and Wu C-Y (2004). Characterization and expression of the pseudorabies virus early gene UL54. J. Virol. Methods 119: 129-136

Jiang YM, Yamada H, Goshima F, Daikoku T, et al. (1998). Characterization of the herpes simplex virus type 2 (HSV-2) US2 gene product and a US2-deficient HSV-2 mutant. J. Gen. Virol. 79: 2777-2784.

Jung JU and Desrosiers RC (1991). Identification and characterization of the herpesvirus saimiri oncoprotein STP-C488. J. Virol. 65: 6953-6960.

Kang M-H and Banfield BW (2010). The pseudorabies virus tegument protein Us2 recruits the MAP kinase ERK to membranes through interaction with the ERK common docking domain. J. Virol. 84: 8398-8408.

Kato K, Cox AD, Hisaka MM, Graham SM, et al. (1992). Isoprenoid addition to Ras protein is the critical modification for its membrane association and transforming activity. Proc. Natl. Acad. Sci. U. S. A. 89: 6403-6407.

Lian B, Xu C, Cheng A, Wang M, et al. (2010). Identification and characterization of duck plague virus glycoprotein C gene and gene product. Virol. J. 7: 349 .

Longnecker R, Chatterjee S, Whitley RJ and Roizman B. (1987). Identification of a herpes simplex virus 1 glycoprotein gene within a gene cluster dispensable for growth in cell culture. Proc. Natl. Acad. Sci. U. S. A. 84: 4303-4307.

Lu L, Cheng A, Wang M, Kiang J, et al. (2010). Polyclonal antibody against the DPV UL46M protein can be a diagnostic candidate. Virol. J. 7: 83.

Luo C, Goshima F, Kamakura M, Mutoh Y, et al. (2012). Immunization with a highly attenuated replication-competent herpes simplex virus type 1 mutant, HF10, protects mice from genital disease caused by herpes simplex virus type 2. Front. 
Microbiol. 3: 158

McGuire JM, Douglas M and Smith KD (1996). The resolution of the neutral N-linked oligosaccharides of IgG by high pH anionexchange chromatography. Carbohydr. Res. 292: 1-9.

Meindl A and Osterrieder N (1999). The equine herpesvirus 1 US2 homolog encodes a nonessential membrane-associated virion component. J. Virol. 73: 3430-3437.

Miller WJ, Skinner JA, Foss GS and Davies KE. (2000). Localization of the fragile X mental retardation 2 (FMR2) protein in mammalian brain. Eur. J. Neuroscience 12: 381-384.

Shen C, Cheng A, Wang M, Sun K, et al. (2010). Development and evaluation of an immunochromatographic strip test based on the recombinant UL51 protein for detecting antibody against duck enteritis virus. Virol. J. 7: 268.

Shen C, Guo Y, Cheng A, Wang M, et al. (2009). Characterization of subcellular localization of duck enteritis virus UL51 protein. Virol. J. 6: 92.

St Clair MH, Lambe CU and Furman PA (1987). Inhibition by ganciclovir of cell growth and DNA synthesis of cells biochemically transformed with herpesvirus genetic information. Antimicrob. Agents Chemother. 31: 844-849.

Tirath S and Sandhu SAM (2008). Diseases of Poultry. Blackwell Publishing, USA.

Towbin H, Staehelin T and Gordon J (1992). Electrophoretic transfer of proteins from polyacrylamide gels to nitrocellulose sheets: procedure and some applications. 1979. Biotechnology 24: 145-149.

Van Beurden S, Peeters B, Rottier P, Davison AJ, et al. (2013). Genome-wide gene expression analysis of anguillid herpesvirus 1. BMC Genomics 14: 83.

Workman JL, Abmayr SM, Cromlish WA and Roeder RG. (1988). Transcriptional regulation by the immediate early protein of pseudorabies virus during in vitro nucleosome assembly. Cell 55: 211-219.

Wu Y, Cheng A, Wang M, Zhang S, et al. (2011). Characterization of the duck enteritis virus UL55 protein. Virol. J. 8: 1-15.

Wu Y, Cheng A, Wang M, Zhang S, et al. (2011). Establishment of real-time quantitative reverse transcription polymerase chain reaction assay for transcriptional analysis of duck enteritis virus UL55 gene. Virol. J. 8: 266.

Wu Y, Cheng A, Wang M, Zhu D, et al. (2012). Comparative genomic analysis of duck enteritis virus strains. J. Virol. 86: $13841-13842$.

Wei S, Liu X, Ma B, Wu Y, et al. (2014). The US2 protein is involved in the penetration and cell-to-cell spreading of DEV in vitro. J. Basic Microbiol. 54: 1005-1011.

Xiang J, Ma G, Zhang S, Cheng A, et al. (2010). Expression and intracellular localization of duck enteritis virus pUL38 protein. Virol. J. 7: 162.

Xiang J, Ma G, Zhang S, Cheng A, et al. (2010) Expression and intracellular localization of duck enteritis virus pUL38 protein. Virol. J. 7: 162.

Xie W, Cheng A, Wang M, Chang H, et al. (2010). Molecular cloning and characterization of the UL31 gene from Duck enteritis virus. Mol. Biol. Rep. 37: 1495-1503.

Xing J, Wang S, Li Y, Guo H, et al. (2011). Characterization of the subcellular localization of herpes simplex virus type 1 proteins in living cells. Med. Microbiol. Immunol. 200: 61-68.

Wu Y, ACC, Wang MS, Zhu DK and Chen XY (2011). Molecular cloning and phylogenetic analysis of the duck enteritis virus UL55 gene. Adv. Materials Res. 204-210: 663-671.

Zhao LC, Cheng AC, Wang MS, Yuan GP, et al. (2008). Identification and characterization of duck enteritis virus dUTPase gene. Avian Dis. 52: 324-331.

Zhou Q, Sun K, Cheng A, Wang M, et al. (2010). Detection of anatid herpesvirus $1 \mathrm{gC}$ gene by TaqManTM fluorescent quantitative real-time PCR with specific primers and probe. Virol. J. 7: 37. 